4 Samanta A, Roy S. Referrals from general practice to a rheumatology clinic. Br $\mathcal{Y}$ Rheumatol 1988;27:74-6.

Stellakis M, Cooper C, Snow S, Kirwan JR. General practitioner referrals to a rheumatology unit. Brf Rheumatol 1990;29:237-8.

6 Helliwell PS, Wright V. Streamlining referrals of rheumatic patients. Pulse 1988;16 April:75-6.

7 Fordham R, Hodkinson C. A cost benefit analysis of open access to physiotherapy for general practitioners. York: Centre for Health Economics, University of York, 1987. (Discussion paper pract

8 Payne S, Ramaiah RS, Jones DT. Open access to orthopaedic appliances for general practitioners. $B M$ F 1987;294:485-6.

9 Joint Working Party between Royal College of General Practitioners and Chartered Society of Physiotherapists. Relationships between general practitioners and chartered physiotherapists. London: Physiotherapists. Relationships between general

10 Billings JRA, Mole KS. Rheumatology in general practice: a survey in world rheumatism year 1977. $\exists R$ Coll Gen Pract 1977;27:271-5.
11 Roland M, Dixon M. Randomised control trial of an educational booklet for patients presenting with back pain in general practice. $f R$ Coll Gen Pract 1989;39:244-6.

12 Wright V, Hopkins R, Burton KE. What shall we teach undergraduates? BMf 1979;i:805-7.

13 Doherty $M$, Abawi J, Pattrick $M$. Audit of medical inpatient examination: a cry from the joint. $f R$ Coll Physicians Lond 1990;24:115-8.

14 Grahame R, Gibson T, Dale E, et al. An evaluated programme of rheumatology training for general practitioners. Br J Rheumatol 1986;25:7-12.

15 Ross AK, Lawton WA. Evaluation of a course for general practitioners on muscles and joints. $B M \mathcal{F}$ 1984;288:609-12.

16 Huston GJ. An offer of rheumatology training: failure to influence clinic referrals. $B M \mathcal{J}$ 1988;296:1773-4.

17 Wright V. The consultant rheumatologist and postgraduate education. BMF 1983;287 $1158-9$.

18 Badley $\mathrm{EM}$, Lee $\mathrm{J}$. The consultants role in continuing medical education of general practitioners: the case of rheumatology. BM7 1987;294:100-3.

\title{
The psychological aftermath of war
}

\section{Battle shock reactions are normal and victims can be helped}

The physical injuries likely to be incurred by casualties of the Gulf war and how to manage them have been widely discussed, ${ }^{1-3}$ but much less has been said about the psychological aftermath. Useful guidelines on managing the psychiatric aspects of disasters have recently been produced, ${ }^{4}$ but the scale of potential injuries in the Gulf war is much greater than in most civil disasters. Although the forces' own medical services will deal with both the immediate management and long term psychiatric care of those who need it, many of the physically injured will also be suffering from battle shock, and those who come through apparently unscathed will be at risk of developing early or late post-traumatic stress disorder.

More than in any other war, both field commanders in the Gulf and the defence medical services are aware of the risks of battle exhaustion and subsequent post-traumatic stress disorder-and of both the personal suffering and the manpower consequences. Battle exhaustion or battle shock is an acute disabling psychological reaction to the horrors of war, but it is a "normal" reaction, and most victims will recover fully. Treatment by the forward medical teams - who are fully aware of the triad of proximity, immediacy, and expectancy ${ }^{5}$ - should result in $70 \%$ of battle shock casualties being returned to their units within five days. A further $10 \%$ will be able to return to other duties, and less than $20 \%$ will need to be passed back for longer term care, mainly in military hospitals and rehabilitation units.

The casualties will be drawn from an atypical population of healthy young men (and some women) who are professionals with a strong service identity. These bonds will have been strengthened by their common experience of combat. They will have more in common with one another than with the rest of the world and have considerable reserves of mutual support.

Thus these military casualties should be kept together in hospital and given an opportunity to socialise with each other and provided with facilities to do so. Those who require treatment away from the main group for clinical reasons should be kept in touch by some means.

As soon as practicable daily "debriefing" sessions should start. These should be held with individuals or service groups and be aimed at encouraging accurate recounting of events and feelings, free emotional expression, and appropriate grieving. Talking to the relatives of dead comrades, attending or watching funerals or memorial services, and creating collages illustrating their experiences or writing about them all help casualties face up to their losses. Though they also need to recognise that their reactions are normal, they will need help in restoring their confidence, morale, and self image. Some will need individual counselling.

Helpers should be advised not to probe too deeply but to limit intervention to dealing with the war experience and current problem solving. Many casualties will express intense guilt and self denigration, but those about them will also have to bear anger, resentment, and derision: "What do you know about it? You weren't there."

Printed handouts can be useful in helping casualties and their relatives understand the reactions they will experience. Relatives can provide support and comfort to each other, and whenever possible a room with simple facilities should be set aside for their exclusive use. They too may need professional and practical help, so social service departments and voluntary agencies should be concerned at an early stage.

The emotional intensity of caring for war casualties will affect staff, who need adequate rest and support with both regular staff groups and individual help if required. The Royal College of Psychiatrists has circulated to all regional medical officers a list of people with particular experience in post-traumatic stress disorder, disaster relief, bereavement, and staff counselling.

Physical casualties may still be in a state of battle shock on arrival in Britain so that intense fear, hyperarousal, and hysterical symptoms including fatigue, amnesia, or loss of motor or sensory function may be present. Others may seem withdrawn, apathetic, or mute. In such cases support, rest, and reassurance are a necessary preliminary to recovery and detailed counselling or exploration must wait.

Post-traumatic stress disorder as described in the Diagnostic and Statistical Manual of Mental Disorders ${ }^{6}$ may develop early or be delayed for months or even years. ${ }^{7}$ The trauma will be persistently re-experienced as recurrent intrusive recollections, recurring dreams or nightmares, flashbacks, or intense distress triggered by events stirring feelings or recollections relating to the original experience. Victims may make efforts to forget or deny the trauma and suffer feelings of detachment, restricted capacity for feelings, and a constriction of interest associated with an inability to contemplate the future. Many show guilt, irritability, insomnia, impaired concentration, and hypervigilance. Counselling should be directed towards limiting or preventing the disorder. The Horowitz impact of events scale $^{8}$ and the general health questionnaire $e^{9}$ may be useful in screening casualties to identify those requiring more intensive intervention.

Some servicemen will undoubtedly reach NHS hospitals. What they need most is first class medical care delivered by caring staff who know how to listen and when to offer 
comfort. All these skills are already available within our existing service.

SYDNEY BRANDON

Postgraduate Dean

University of Leicester School of Medicine,

Leicester LE2 7LX

1 Murray VSG, Volans GN. Management of injuries due to chemical weapons. BMf 1991;302:129-30. 2 Yates DW. The NHS prepares for war. BMF 1991;302:130.
Delamothe T. The war at home $B M 7$ 1991:302.201.

Psychiatric aspects of disaster. $\mathcal{I} R$ Soc Med 1990;84:2-25.

Artiss KL. Human behavior under stress - from combat to social psychiatry. Milit Med 1963;128 $1011-5$

6 American Psychiatric Association. Diagnostic and statistical manual of mental disorders third edition revised. Washington, DC: APA, 1987.

Solomon Z, Koller M, Shaler A, Lin R. Delayed onset PTSD among Israeli veterans of the 1982 Lebanon war. Psychiatry 1989;54:428-36.

8 Horowitz $M$, Wilner $N$, Alvarez W. Impact of event scale: a measure of subjective distress. Psychosom Med 1979;41:209-18.

9 Goldberg DP, Hillier VF. A scaled version of the general health questionnaire. Psychol Med 1979;9:139-45.

\title{
Teaching junior doctors practical procedures
}

\author{
"See one, do one, teach one" will no longer do
}

Junior doctors are not only overtired from working long hours but are also dissatisfied with the quality of their work. ${ }^{1}$ House officers complain that too much time is spent on chasing results and organising beds and too little on training-particularly on being taught practical procedures.

Poor performance at resuscitation illustrates well the inadequacy of practical teaching. The problem was first noticed at least five years ago, and courses were recommended to improve juniors' skills. ${ }^{2}$ But despite this, performance remains poor. ${ }^{1}$ Furthermore, the experience gained by attending cardiac arrests has not been shown to be a substitute for proper training, ${ }^{3}$ scuppering the shibboleth "see one, do one, teach one."

Not only junior doctors are unhappy. Patients now have greater expectations and are increasingly taking their cases to the courts. ${ }^{+}$The threat of negligence claims and the risks of complications might both diminish if junior doctors called for help when in trouble, but many fail to do so-either through overconfidence or through reluctance to disturb their seniors. This problem is compounded if seniors fail to attend when summoned. ${ }^{5}$ In a recent survey on urethral catheterisation seven of the 30 house officers questioned had not wanted to seek advice "because of their impression that difficulties with catheterisation were not worthy of disturbing senior staff." Overall, 25 had caused complications during catheterisation. Supervision was poor: four had never been supervised, and 24 had been supervised only once. The General Medical Council recommends that experience in the preregistration year should be acquired under the supervision of consultants and other senior medical staff. ${ }^{7}$ A survey in Liverpool, however, showed that $85 \%$ of the 115 house officers questioned received most of their teaching from other junior doctors and $62 \%$ had learnt "a lot" from the nursing staff. ${ }^{8}$

Sadly, problems may worsen because house officers are likely to gain less and less experience in future on the wardsa phenomenon already recognised in the United States. ${ }^{9}$ The emphasis on patient care is shifting from the wards to outpatient departments, and unless house officers spend more time in clinics the opportunity for them to learn on the job will decline.

Exposing house officers to more practical procedures during the undergraduate years would be one way of improving their preparation, especially for facing patients alone and at night. As undergraduates they are free to ask questions without the fear of disturbing the sleep of registrars and may familiarise themselves with equipment. A survey of London graduates confirmed that they would have preferred better practical training at medical school. ${ }^{10}$ But however desirable this may be, the difficulty remains of declining numbers of inpatients available for teaching.

The medical school at Maastricht in The Netherlands has found a way round using patients as teaching aids by pioneering a skills laboratory for training undergraduates. Models are used to acquire skills: students may practise inserting cannulas into plastic arms, learn to use an ophthalmoscope on a model eye, perform a vaginal examination on a plastic pelvis, and resuscitate a manikin. Communication skills using role playing and real patients are also taught. ${ }^{11}$ Simulated learning is not new to Britain and is already used in surgical training, ${ }^{12}$ but up until now it has not been established in the undergraduate curriculum. Plans are, however, already underway for the first skills centre run along the Maastricht lines to open at St Bartholomew's Hospital in London next year.

But changes also bring problems. Juniors must be wary that their hard won agreement over hours could jeopardise their opportunity to gain practical experience. Danish doctors confronted the problem of long hours 10 years ago. Their working week is now reduced to 37 hours, but after six years' training a registrar may have performed only two or three cholecystectomies. ${ }^{13}$

Many changes are taking place in the NHS and it is up to the General Medical Council, the royal colleges, the BMA, and the medical schools to make sure that juniors' training does not suffer along the way.

Medical registrar, $B M \mathcal{F}$

ALISON WALKER

Dent THS, Gillard JH, Aarons EJ, Crimlisk HL, Smyth-Pigott PJ. Preregistration house officers in the four Thames regions: I. Survey of education and workload. $B M 7$ 1990;300:713-5.

Skinner DV, Camm AJ, Miles S. Cardiopulmonary resuscitation skills of preregistration house officers. BMF 1985;290:1549-50.

$3 \mathrm{Kaye} W, \mathrm{~W}$ ynne G, Marteau T, et al. An advanced resuscitation training course for preregistration house officers. I $R$ Coll Physicians Lond 1990;24:51-4

4 King's Fund Institution and the Centre for Sociolegal Studies, Oxford. Medical negligence compensation and accountability. London: King's Fund, 1988

Ennis M, Vincent CA. Obstetric accidents: a review of 64 cases. BMF 1990;300:1365-7.

6 Carter R, Aitchison M, Mufti GR, Scott R. Catheterisation: your urethra in their hands. BM 1990;301:905.

General Medical Council Education Committee. Recommendations on basic medical education London: General Medical Council, 1980.

8 Elizabeth JE, Hughes $S$. An assessment of the preregistration experience. BMF 1986;293:1559.

9 Schroeder SA, Showstack JA, Gerbert B. Residency training in internal medicine: time for change? Ann Intern Med 1986;104:554-61.

10 Jolly $B C$. Macdonald MM. Education for practice: the role of practical experience in undergraduate and general clinical training. Med Educ 1989;23:189-95.

1 and general clinical trails teaching at Maastricht medical school. Med Educ 1989;23:55-61.

2 Macil IMC, Munro A. Simulation in surgical training. BMf 1990;300: 1088-9.

13 Hoffman J, Fischer A. Juniors' hours. BMJ 1990;301:1159. 